\title{
Correlation between clinical neurological data and urodynamic function in spinal cord injured patients
}

\author{
JJ Wyndaele
}

\author{
Department of Urology, University of Antwerp, University Hospital, B2650 Edegem, Belgium
}

\begin{abstract}
In 92 patients with spinal cord lesion, out of spinal shock, the data from a clinical neurological examination of the lumbosacral area are compared with the data from a full urodynamic investigation, including evaluation of sensation in the lower urinary tract. A significant correlation can be found between different levels of spinal cord lesion, the function of bladder neck and sphincter and the anal bulbocavernosus reflexes. Higher lesions correspond more with a reflexic lower urinary tract and somatic motor activity, lower lesions more with areflexia. With a lesion between thoracic 10 and lumbar 2 as many reflexic as areflexic lower urinary tract dysfunctions were found. The presence or absence of perineal sensation of light touch corresponded significantly with the presence or absence of sensation in the lower urinary tract. Detrusor and striated sphincter reflexia/areflexia corresponded significantly with the presence/absence of bulbocavernosus and anal reflexes. Clinical neurological examination gives useful information which acceptably corresponds with the LUT function. However to decide on a detailed individual diagnosis, clinical examination is in our opinion insufficient. Urodynamic tests are needed for a profound evaluation of the function of different parts of the lower urinary tract and their interaction.
\end{abstract}

Keywords: spinal cord injury; clinical neurological aspects; neuropathetic bladder; urodynamics

\section{Introduction}

The incidence of neuropathic dysfunction of the lower urinary tract (LUT) in patients with a spinal cord lesion (SCL) is high. Moreover, the overall prognosis of these patients depends for a major part on the urological treatment, which itself should be based on an accurate diagnosis of the impairement of the LUT function. $^{1-3}$

After SCL the clinical function neurological signs and the dynamic status of the bladder/urethra both depend on the level, the extent and the completeness of the lesion. ${ }^{4}$

In the literature, authors present data from a clinical neurological examination and data from urodynamic studies as important or as of limited diagnostic use in the evaluation of LUT function after SCL. ${ }^{5,6}$

In this study we compare the two groups of data in SCL patients in order to evaluate a possible correlation between them and the diagnostic value of clinical data in relation to LUT function.

\section{Patients and methods}

Ninety-two patients with traumatic SCL were included at random. They were 70 male and 22 female patients, mean age 37 years old (from 9 to 75 years). All were out of spinal shock, with a period of 6 months and 40 years between trauma and investigation. The level of the spinal cord lesion is given in Table 1. Fifty patients had a neurological lesion corresponding with score A on the ASIA/IMSOP classification (motor and sensory function absent under the lesion), 42 had a non $\mathrm{A}^{7}$

The neurological examination consisted of the evaluation of the sensation of light touch on the perineum and dorsal side of both legs, bulbocavernosus (BCR) and anal (AR) reflexes, volitional contraction of the anal sphincter (AC). In male patients cremasteric reflexes were evaluated on both sides. ${ }^{8}$

The technical video-urodynamic investigation was performed as described before. ${ }^{9}$ Evaluation of the afferent innervation of the LUT was performed with the determination of filling sensation and in a limited number of patients with the determination of the thresholds for electrical stimulation. ${ }^{10}$

The following urodynamic diagnoses are used: for the detrusor: normal (= volitional start of micturition), hyperreflexic, areflexic; for the bladder neck: dyssynergic (= not opening at detrusor contraction), synergic (=opening at detrusor contraction), incompetent (=always open); for the urethral striated sphincter: synergic, dyssynergic (including non relaxing and intermittently relaxing during micturition), incompetent ( = flaccid paralysis). Most of these follow the definitions as proposed by the International Continence Society. ${ }^{11}$

None of the patients included had previous surgery 
on the LUT. Medication intake with known action on LUT function was reason for non inclusion. Some data are missing in some patients: the equipment for determination of electrosensation and for X-rays were available only during a part of the study. The statistical analysis was done in SPSS 6.1 with ChiSquare. A significance level of $P<0.05$ is accepted.

\section{Results}

Patients were divided into four groups depending on the level of SCL: cervical, thoracic above T10, from T10 to L2 included, under L2.

The data from the urodynamic LUT function and the neurological examination in these four SCL-level groups are given in Tables 2 and 3 . Two male patients with a SCL T9 had a cremasteric reflex present at only one side. Two other patients had had the right testicle removed during childhood. In nine patients only one of BCR and AR was present (six with $\mathrm{AR}+$ and $\mathrm{BCR}-$, three with $\mathrm{AR}-$ and $\mathrm{BCR}+$ ).

Though a reflexic detrusor (normal or hyperreflexic) was present in $70 \%(37 / 53)$ of patients with a SCL higher than T10, and 4/5 with a SCL below L2 had an areflexic detrusor, the type of LUT function was not statistically significant different between different SCL levels.

The bladder neck and sphincter function distribution was statistically significant different between SCL levels. Above T10 71\% competent bladder neck and $85 \%$ active striated sphincter; below L2 4/4 incompetent bladder neck and $2 / 3$ incompetent sphincter.

With the SCL between T10 and L2, the reflexic/ areflexic ratio was for the detrusor $17 / 16$. In this group of patients the active/incompetent ratio was for the bladder neck 19/12, for the sphincter $20 / 11$. In the 17 patients with detrusor hyperreflexia, six had a synergic sphincter, 10 a dyssynergic sphincter and one flaccid paralysis of the external sphincter. An active bladder neck was found in 14 patients and an incompetent bladder neck in three patients.

Table 1 Localisation of the spinal cord lesion

\begin{tabular}{lccccc}
\hline & \multicolumn{2}{c}{ Cervical } & \multicolumn{2}{c}{ Thoracic } & \multicolumn{2}{c}{ Lumbar } \\
Level & Number & Level & Number & Level & Number \\
\hline 1 & - & 1 & 1 & 1 & 6 \\
2 & 2 & 2 & 3 & 2 & 7 \\
3 & - & 3 & 4 & 3 & 1 \\
4 & 5 & 4 & 2 & 4 & 4 \\
5 & 4 & 5 & 2 & & \\
6 & 5 & 6 & 7 & & \\
7 & 2 & 7 & 8 & & \\
8 & 1 & 8 & 5 & & \\
& & 9 & 3 & & \\
& & 10 & 6 & & \\
& & 11 & 6 & & \\
Total & 19 & 12 & 8 & & \\
\hline
\end{tabular}

In 14 of 16 patients with detrusor areflexia information on the striated sphincter is available: dyssynergic in four patients and flaccid in 10 patients. Data on bladder neck function are available in 14 of the 16 patients with detrusor areflexia: active in five and incompetent in nine patients.

Perineal sensation and sensation in the LUT are correlated in Table 4. Filling sensation is pathological but present in 11/48 (SCL in six above T9, in four between T10-L2, in one below L2), electrosensation in 9/20 (normal in two with SCL above T9, in one

Table 2 Urodynamic function of the LUT found in patients with different levels of SCL

\begin{tabular}{lrrrc}
\hline & $C 1-C 8$ & $T 1-T 9$ & $T 10-L 2$ & $<\mathrm{L} 2$ \\
\hline Detrusor & & & & \\
$\quad$ Normal & 1 & 1 & 2 & \\
$\quad$ Hyperreflexic & 12 & 23 & 15 & 1 \\
$\quad$ Areflexic & 6 & 10 & 16 & 4 \\
$\quad$ ? & & 1 & & $\mathrm{NS}$ \\
Bladder Neck & & & & \\
$\quad$ Synergic & 7 & 19 & 18 & \\
Dyssynergic & 2 & 1 & 1 & \\
Incompetent & 7 & 5 & 12 & 4 \\
$?$ & 3 & 10 & 2 & 1 \\
Sphincter & & & & $P<0.05$ \\
Synergic & 5 & 3 & 6 & \\
Dyssynergic & 9 & 24 & 14 & 1 \\
Incompetent & 4 & 3 & 11 & 2 \\
$?$ & 1 & 5 & 2 & 2 \\
& & & & $P<0.05$ \\
\hline
\end{tabular}

$\mathrm{NS}=$ statistically not significantly

Table 3 Data from the neurological examination found in patients with different levels of SCL

\begin{tabular}{lcccc}
\hline & $C 1-C 8$ & $T 1-T 9$ & $T 10-L 2$ & $<\mathrm{L} 2$ \\
\hline Anal Reflex & & & & \\
- & 5 & 8 & 20 & 5 \\
+ & 14 & 26 & 13 & \\
$?$ & & 1 & & \\
Bulboc.Refl. & & & $P<0.005$ & \\
- & 4 & 1 & 24 & 5 \\
+ & 14 & 27 & 9 & \\
$?$ & 1 & 1 & & \\
& & & $P<0.005$ & \\
Cremast.L & 8 & 9 & 5 & 1 \\
- & 8 & 17 & 19 & 1 \\
+ & & & NS & \\
Cremast.R & & 7 & 5 & 1 \\
- & 8 & 20 & 19 & 2 \\
+ & & & NS & \\
\hline
\end{tabular}

$\mathrm{NS}=$ niet significant. Bulboc. Refl. $=$ bulbocavernosus reflex. Cremast. $=$ cremasteric reflex $. \mathrm{L}=$ left side; $\mathrm{R}=$ right side 
between T10-L2, in one below L2, pathological in two above T9, in two between T10-L2) of patients with absent sensation of touch of the perineum.

The correlation between $\mathrm{BCR} / \mathrm{AR}$ evaluated clinically and the LUT function is given in Table 5. A statistical significance is found with detrusor function and with the function of the striated sphincter.

Between the cremasteric reflexes and the function of the bladder neck no correlation can be found.

\section{Discussion}

The early descriptions of voiding dysfunction in patients with SCL were determined by the findings on neurological examinations. Bors and Comarr ${ }^{4}$ classified the neurological lesions as either upper or lower motor neuron with respect to the anatomical

Table 4 Perineal sensation and sensation in the LUT

\begin{tabular}{lcrcc}
\hline Sensation LUT & \multicolumn{4}{c}{ Perineal sensation } \\
& Normal & Pathological & Absent & ? \\
\hline Filling & & & & \\
$\quad$ Normal & 4 & 4 & & \\
Pathological & 9 & 13 & 11 & \\
Absent & 3 & 9 & 37 & 2 \\
& & & $P<0.001$ & \\
Electro & & 12 & 5 & \\
$\quad$ Normal & 11 & 6 & 4 & \\
Pathological & & 3 & 11 & \\
Absent & & 5 & 28 & 2 \\
? & 5 & & $P<0.001$ & \\
& & &
\end{tabular}

Table 5 Bulbocavernosus and anal reflex compared with urodynamic LUT function

\begin{tabular}{|c|c|c|c|c|}
\hline & \multicolumn{4}{|c|}{$B C R$ and $A R$} \\
\hline & $+1+$ & $-1-$ & $+1-$ & $?$ \\
\hline \multicolumn{5}{|l|}{ Detrusor } \\
\hline Normal & 1 & 1 & 2 & \multirow{5}{*}{2} \\
\hline Hyperreflexic & 34 & 8 & 6 & \\
\hline Areflexic & 11 & 25 & 1 & \\
\hline \multirow[t]{2}{*}{ ? } & 1 & & & \\
\hline & & \multicolumn{2}{|c|}{$P<0.001$} & \\
\hline \multicolumn{5}{|l|}{ Bladder neck } \\
\hline Synergic & 25 & 12 & 6 & 1 \\
\hline Dyssynergic & 3 & 1 & & \\
\hline Incompetent & 11 & 17 & & \\
\hline$?$ & 8 & 4 & $\begin{array}{c}3 \\
\text { NS }\end{array}$ & 1 \\
\hline \multicolumn{5}{|l|}{ Sphincter } \\
\hline Synergic & 9 & 3 & 2 & \\
\hline Dyssynergic & 30 & 11 & 5 & 2 \\
\hline Incompetent & 4 & 15 & 1 & \\
\hline$?$ & 4 & 5 & $\begin{array}{c}1 \\
P<0.05\end{array}$ & \\
\hline
\end{tabular}

$+/-=$ only one is present. $\mathrm{NS}=$ statistically not significant relationship of the injury to the sacral cord reflex centres. It is known from clinical experience, and this has also been demonstrated in animal experiments, that the spinal micturition reflex pathway is essential for the development of automatic voiding after SCL and that the bladder may become hyperreflexic. ${ }^{12}$ The parasympathetic preganglionic nerves arise in humans from the S2-S4 spinal cord segments. ${ }^{13}$ Most preganglionic sympathetic neurones arise from T10-L2 and provide an excitatory input to the bladder neck and urethra to maintain closure of the outlet. ${ }^{14}$ Finally the somatic motor supply to the striated muscles of the pelvic floor and intrinsic external urethral sphincter is generally regarded to originate from S2-S4. ${ }^{13}$ Theoretically lesions of the vertebrae above T10 should give an hyperreflexic activity in the LUT, those below L2 should provoke areflexia. Our data show that such is indeed the case, however only a very small number of patients with a lesion below L2 were included. In a previous series of 103 patients, the correlation between the type of bladder dysfunction and the level of the SCL was even better. ${ }^{15}$ Bladder areflexia and a flaccid paralysis of the striated sphincter may occur due to vascular damage of the cord under the lesion in up to one third of the cases. ${ }^{4}$ The coexistence of a second subclinical lesion at a different level, a variability in cord to column correlation and damage to the detrusor muscle from overdistension, eg during spinal shock may be other cause of areflexia.

It has been demonstrated that the prognosis after SCL depends amongst others of the completeness of the lesion. ${ }^{16}$ The term complete lesion is commonly used when there is an absence of somatosensory and motor function in the lowest sacral segments. ${ }^{17}$ The preservation of perineal sensation to light touch and the voluntary contraction of the external anal sphincter define the injury as incomplete. Data from our study show that the completeness of the lesion as determined by neurological examination does not correspond with an absence of filling sensation/ electrosensation in at least $25 \%$ of the patients. In this group with preserved sensation all levels of SCL are present. That neurological pathways can be spared after spinal cord injury has recently again been demonstrated neurophysiologically in animal experiments. ${ }^{18}$ From our data it would seem advisable that completeness of a spinal cord lesion should only be accepted after evaluation of LUT sensation. ${ }^{10}$

The bulbocavernosus reflex extends from L5 to S5, the anal reflex arc being also in the lower sacral segments. Investigating these reflexes will theoretically inform about the preservation or damage of the lower spinal cord and thus about the innervation of bladder and striated sphincter. While present reflexes correspond in the majority of our patients with a reflex activity in the LUT, such correlation is not found in all patients. The reason for this could be the reduction or absence of clinical detectable reflexes in up to $30 \%$ of persons with an intact neuraxis. ${ }^{4}$ Blaivas et al ${ }^{19}$ state however that the absence of the bulbocavernosus 
reflex particularly in a male patient must be considered as highly suggestive of a neurologic lesion of the conus or caude equina. Our data would seem to contradict this statement.

The nerves involved in the cremasteric reflexes and the sympathetic innervation of the LUT are located in the same part of the spinal cord. Our data however show no correlation between presence or absence of cremasteric reflexes and bladder neck function.

To conclude, we think that the data from this study again show that clinical neurological examination of a patient after SCL is also valuable for the diagnosis of LUT function. As written by Diokno ${ }^{5}$ no tests are easier to perform or can be accomplished more quickly. But our data show also that neurological examination alone is insufficient in accurately classifying bladder behaviour following SCL, especially but not exclusively in those patients with paraplegia who present with spinal cord lesions from T10-L2.

As stated already by Markland et $a{ }^{20}$ physical examination findings do not necessarily reflect visceral function, and therapeutic considerations should not depend solely on these findings. In this aspect we would also plead for a good evaluation of LUT sensation which can easily be done during routine urodynamics.

\section{References}

1 Barkin M et al. The urological care of the SCI patient. J Urol 1983; 129: 335 - 339 .

2 Madersbacher $H$. The various types of neurogenic bladder dysfunction an update of current therapeutic concepts. Paraplegia 1990; 28: $217-229$.

3 Bors E, Comarr AE. Disturbances of micturition. Symptoms, signs and general management. In: Bors E, Comarr AE, (eds). Neurological Urology. Karger: Basel 1971, pp 181-184.

4 Hackler RH. A 25 year prospective mortality study in the spinal cord injury patient. Comparison with the longterm living paraplegic. J Urol 1977; 117: 486-488.
5 Diokno A. Neurological examinations. In: Yalla S, McGuire E, Elbadawi A, Blaivas J (eds). Neurourology and Urodynamics. Principles and practice. MacMillian: New York 1988, pp 150154.

6 Staskin D, Krane R. A practical approach to urodynamic evaluation. In: Parsons K, Fitzpatrick J (eds). Practical Urology in SCI. Springer: London 1991, pp 11-26.

7 Ditunno J, Young W, Donovan W, Creasey G. The international standards booklet for neurological and functional classification of spinal cord injury. Paraplegia 1994; 32: 70-80.

8 Comarr AE. The practical urological management of the patient with SCI. Br J Urol 1959; 31: 1 - 46.

9 Wyndaele JJ. A clinical study on subjective sensations during bladder filling. Int Urogynecol J 1991; 2: 215-218.

10 Wyndaele JJ. Investigation of the afferent nerves of the lower urinary tract in patients with'complete' and 'incomplete' spinal cord injury. Paraplegia 1991; 29: 490-494.

11 Abrams P, Blaivas J, Stanton S, Andersen J. The standardisation of terminology of lower urinary tract function recommended by the International Continence Society. Int Urogynecol J 1990; 1: $45-48$.

12 de Groat $\mathrm{W}$ et al. Parasympathetic preganglionic neurons in the sacral spinal cord. J Auton Nerv System 1982; 5: 23 - 43.

13 Fletcher T, Bradley W. Neuroanatomy of the bladder/urethra. $J$. Urol 1978; 119: $153-160$.

14 Krane R, Olsson C. Phenoxybenzamine in neurogenic bladder dysfunction. I. A theory of micturition. J Urol 1973; 110: $650-$ 652.

15 Wyndaele JJ. A critical review of urodynamic investigations in spinal cord injury patients. Paraplegia 1984; 22: $138-144$.

16 Maury M. Le Pronostic. In: Maury M (ed). La paraplégie. Flammarion: Paris 1981, ch 10, p 146.

17 Waters R, Adkins R, Yahura J. Definition of complete spinal cord injury. Paraplegia 1991; 29: 573-581.

18 Haghihi S et al. Neurophysiological evidence of spared upper motor neurons after spinal cord injury. Paraplegia 1996; 34: 39 45.

19 Blaivas J, Zayed A, Labib K. The bulbocavernosus reflex in urology: a prospective study of 299 patients. J Urol 1988; 126: $197-199$.

20 Markland C, Chou S, Bradley W. Neuro-urological evaluation of neurogenic bladder dysfunction. In: Boyarski $\mathrm{E}$ (ed). The neurogenic bladder. Williams-Wilkins: Baltimore 1967, pp $115-$ 122 . 